\title{
Characterization of laser-borided Nimonic 80A-alloy
}

\author{
Piotr Kieruj ${ }^{1, *}$, Natalia Makuch $^{2}$, and Mateusz Kukliński ${ }^{1}$ \\ ${ }^{1}$ Institue of Mechanical Technology, Faculty of Mechanical Engineering and Management, Poznan \\ University of Technology, Poland \\ ${ }^{2}$ Institue of Material Engineering, Faculty of Mechanical Engineering and Management, Poznan \\ University of Technology, Poland
}

\begin{abstract}
Nimonic $80 \mathrm{~A}$-alloy belongs to Nickel-based superalloys. Many of them are used in variety branches of industry due to high strength and resistance in aggressive conditions. Moreover, its mechanical properties are kept in high temperature. However, these materials should be coated by appropriate wear protection, under conditions of considerable mechanical wear. Unfortunately, the production of thick borided layer in diffusion boriding required high temperature and long duration of this processes. Therefore, in this study instead conventional diffusion process laser boriding was applied in order to produce boride layer on Nimonic 80Aalloy substrate. Laser alloying is the high-tech process which allows to modify the chemical composition of the surface. Laser boriding was arranged as a single tracks, therefore it was possible to evaluate the influence of laser treatment parameters on thickness and hardness of produced layers. The laser beam power $P$, laser scanning speed $\underline{v_{l}}$ and laser beam diameter $d_{l}$ were the variable parameters used during laser alloying.
\end{abstract}

\section{Introduction}

All of nickel alloys are known of their corrosion resistance and good strength properties, also in very high temperatures. Unfortunately, they are characterized by low hardness and wear resistance and thus their application is limited. They cannot be used for machine parts which cooperates with each other by sliding because it rapidly leads to damage of surface and sudden increase of roughness. Formation of grooves on cooperating machine parts results in stalling and breakdown.

Methods of thermo-chemical treatment allow to increase the durability of parts which are subjected to the large surface pressure. Effects of carburizing these alloys are unsatisfactory. The process is long-standing, even over $200 \mathrm{~h}$, besides metal carbides formed in grain boundaries chromium and alumina oxides are built and the mass increase caused by carbon saturation is very low [1]. Additionally, produced layer [2] has the form of coating and is not strongly bonded with the substrate. It results in roughness increase of workpiece and requires grinding aimed to provide relevant surface quality. In case of nickel alloys, plasma nitriding is applied [3,4,5]. Unfortunately, this process lasts even over $20 \mathrm{~h}$ [4]. Obtained nitrided layers thicknesses depend on kind of nickel alloy, time of treatment

\footnotetext{
*Corresponding author: piotr.a.kieruj@doctorate.put.poznan.pl
} 
and process temperature [3,5]. After $4 \mathrm{~h}$ of the process it is possible to obtain layer $6 \mu \mathrm{m}$ thick [3]. Increase in hardness in relation to the substrate is low, to $30 \%$, and is conjugated to increase of surface roughness [4].

There are some methods of diffusion boriding which have different sources of boron atoms - gas, paste, electrochemical or multi-stage processes. Relevant treated material allows to obtain very hard layer which is wear resistant. However, high hardness make fundamental technological problems with can occurring during the machining are related to the difficulties in obtainment of high machined surface finish and heavy tools wear. Therfore, the machine components with laser borided layers belong to the group of materials coaled hard to cut, like cemented carbide [22], Inconel 718 [24], Waspaloy [25], MMC [26] or ceramic $\mathrm{Si}_{3} \mathrm{~N}_{4}$ [27]. Borided layers are characterized with greater durability than nitrided, carburized or nitro-carburized layers [7]. Particularly good properties can be obtained by boriding nickel alloys. Then, in surface layer very hard borides are formed which improve strength parameters. Diffusion boriding is widely described in literature [7]. In general, all nickel alloys which are applied in industry can be borided by diffusion and gained effects depend on chemical composition and process flow. Thicknesses of layers of increased hardness are several times greater than in different thermo chemical processes.

Laser heat treatment, laser alloying and laser cladding allow to modify structure and properties of construction materials [23, 13]. Besides obtaining good effects of diffusion boriding, this process still has a significant disadvantage - it is long-standing. Adapting laser beam to thermo chemical treatment and development of laser boriding is an expansion of the process. In recent years, laser boriding of different ferrous [16] and titanium alloys $[17,19]$ is intensively improved as the most effective method of forming borided layers. There is no many studies on laser boriding of nickel alloys. The main advantages of laser boriding are the process speed and possibility of selective laser treatment of specified areas. Smooth adjustment of parameters in a wide range provides process flexibility.

Method applied in aforementioned experimental studies are two-stage. In first stage, layer of paste including amorphous boron is deposited on surface of treated object. Second stage is treatment of object with paste using laser beam. After solidification, layer of properties different than boron and the substrate is obtained. These properties depend on laser treatment parameters which impact heating, melting, mixing and solidification processes. It has an influence on structure, thickness, stresses and utility properties of layer.

In existing research papers, nickel alloy Inconel 600 was laser borided [20]. Nickel alloy Nimonic 80A was laser alloyed with boron and niobium [21]. In this case the method of conducting research was similar as in aforementioned article on Inconel 600 [20]. Composition of paste was different. Paste included boron and niobium of 1:1 mass ratio.

The main objective of this research was examination of laser treatment parameters (laser beam power $P$, laser beam scanning velocity $v_{l}$, laser beam diameter on surface of treated object $d_{l}$ ) influence on microhardness of structure and geometrical features of re-melted areas (tracks). Because of investigative character of research, it was decided to apply boron layer of low thickness. Furthermore, microstructure was analyzed and discussed.

\section{Details of research}

\subsection{Treated material}

Nimonic 80A was investigated. Chemical composition of this alloy is shown in Table 1. Rectangular specimens of equal dimensions (length $30 \mathrm{~mm}$, width $20 \mathrm{~mm}$, height $12 \mathrm{~mm}$ ) were used in research. In order to reduce reflectiveness and to provide independence of results from surface quality, each specimen was grinded in same conditions. 
Table 1. Chemical composition of Nimonic 80A-alloy (weight \%).

\begin{tabular}{|c|c|c|c|c|c|c|c|c|c|c|c|c|}
\hline $\mathrm{Ni}$ & $\mathrm{Cr}$ & $\mathrm{Ti}$ & $\mathrm{Al}$ & $\mathrm{Fe}$ & $\mathrm{Co}$ & $\mathrm{Mn}$ & $\mathrm{Si}$ & $\mathrm{Cu}$ & $\mathrm{Zr}$ & $\mathrm{C}$ & $\mathrm{S}$ & $\mathrm{B}$ \\
\hline \multirow{2}{*}{ balance } & $18,0-$ & $1,8-$ & $1,0-$ & $\max$. & $\max$. & $\max$. & $\max$. & $\max$. & $\max$ & $\max$ & $\max$. & $\max$. \\
& 21,0 & 2,7 & 1,8 & 3,0 & 2,0 & 1,0 & 1,0 & 0,2 & 0,15 & 0,1 & 0,015 & 0,008 \\
\hline
\end{tabular}

\subsection{Laser boriding}

Two-stage laser boriding was carried out. At first stage, rectangular specimens were covered with paste including amorphous boron of particle size lower than $1 \mu \mathrm{m}$. Matrix for amorphous boron was water glass (sodium silicate). Layers of boron paste had average thickness of $30 \mu \mathrm{m}$. After drying of paste laser treatment was performed (second stage) in accordance with research program shown in Table 2.

Table 2. Research program.

\begin{tabular}{|c|c|c|c|}
\hline Constants & \multicolumn{3}{|c|}{ Variables / Designations of attempts } \\
\hline$d_{l}=1,5 \mathrm{~mm}$ & $P=1,04 \mathrm{~kW}$ & $P=1,56 \mathrm{~kW}$ & $P=2,08 \mathrm{~kW}$ \\
$v_{l}=2,56 \mathrm{~m} / \mathrm{min}$ & $1 \mathrm{~A} 1$ & $1 \mathrm{~A} 2$ & $1 \mathrm{~A} 3$ \\
\hline$P=1,56 \mathrm{~kW}$ & $v_{l}=1,28 \mathrm{~m} / \mathrm{min}$ & $v_{l}=2,56 \mathrm{~m} / \mathrm{min}$ & $v_{l}=3,84 \mathrm{~m} / \mathrm{min}$ \\
$d_{l}=1,5 \mathrm{~mm}$ & $2 \mathrm{~A} 1$ & $2 \mathrm{~A} 2$ & $2 \mathrm{~A} 3$ \\
\hline$P=1,56 \mathrm{~kW}$ & $d_{l}=1,00 \mathrm{~mm}$ & $d_{l}=1,50 \mathrm{~mm}$ & $d_{l}=2,00 \mathrm{~mm}$ \\
$v_{l}=2,56 \mathrm{~m} / \mathrm{min}$ & $3 \mathrm{~A} 1$ & $3 \mathrm{~A} 2$ & $3 \mathrm{~A} 3$ \\
\hline
\end{tabular}

Treatment was carried out with three values of each from three process variables. First variable was laser beam power $P$, second was laser beam scanning velocity $v_{l}$, and third laser beam diameter on treated surface $d_{l}$. Scheme of the process is presented in Figure 1.

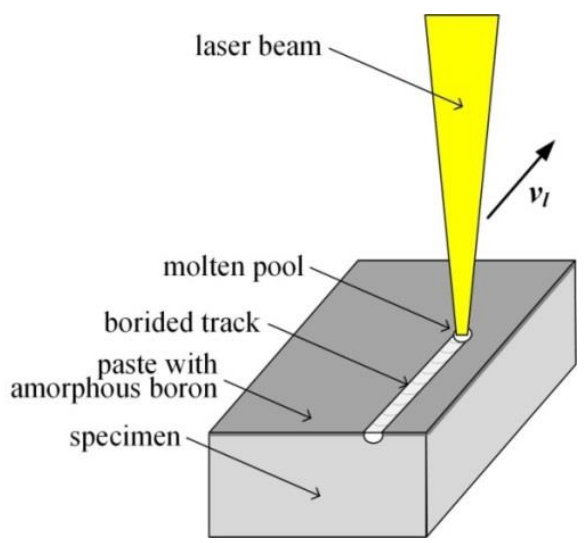

Fig. 1. Scheme of two-step method of laser boriding.

Laser boriding was performed using $\mathrm{CO}_{2}$ molecular laser TRUMPF 2600 TURBO. Nominal power of the laser is $2,6 \mathrm{~kW}$ and has smooth adjustment of power in whole range. This laser is characterized by cylindrical symmetric transverse mode of laser beam TEM01*. This distribution is characterized by energy which goes to zero in center of laser beam. Laser mode TEM01* occurs due to connection of two modes TEM01 rotated by $90^{\circ}$ angularly. Laser beam power density is ranged from $49,66 \mathrm{~kW} / \mathrm{cm}^{3}\left(P=1,56 \mathrm{~kW}, d_{l}=2\right.$ $\mathrm{mm})$ to $198,63 \mathrm{~kW} / \mathrm{cm}^{3}\left(P=1,56 \mathrm{~kW}, d_{l}=1,0 \mathrm{~mm}\right)$. Linear energy of laser beam is ranged from $24,38 \mathrm{~J} / \mathrm{mm}\left(P=1,56 \mathrm{~kW}, v_{l}=3,84 \mathrm{~m} / \mathrm{min}\right)$ to $73,13 \mathrm{~J} / \mathrm{mm}\left(P=1,56 \mathrm{~kW}, v_{l}=1,28\right.$ 
$\mathrm{m} / \mathrm{min})$. On one surface of specimen (20x30) three passes were performed, set at a distance of $4 \mathrm{~mm}$ between one another's axis. Protective atmosphere of inert gas was not applied.

\subsection{X-Ray microanalysis, phase analysis and geometrical parameters}

After laser boriding, metallographic micro-sections were prepared. Specimens were cut perpendicular to the laser treatment and treated surface. Due to small dimensions, specimens were included in resin. Then, specimens were wet grinded with abrasive papers and thereafter polished using $\mathrm{Al}_{2} \mathrm{O}_{3}$. Specimens were etched with Marble's reagent. Micro sections were observed with optical microscope OPTA-TECH Lab40 and scanning electron microscope Tescan Vega 5135 where direction of scanning was perpendicular to surface.

Content of dominant elements in Nimonic 80A alloy: nickel, chromium, titanium and alloying element - boron, in borided layer, was measured using PGT Avalon X-ray microanalyzer equipped with EDS detector. Applied take-off angle was $55^{\circ}$ and accelerating voltage was equal to $12 \mathrm{kV}$. Measurements were carried out in three different points corresponding to different structural phases visible in SEM pictures.

During observation of laser tracks' cross sections manufactured on the surface during laser boriding, measurements of depth and width of re-melting were carried out. Width of laser track $b$ is the highest dimension of re-melting measured on the surface of specimen. Depth $h$ is a distance between the surface and a boundary of re-melting and the substrate with unmodified structure, measured in the axis of laser track, symmetric to its width.

\subsection{Microhardness profile}

The objective of microhardness measurements was to create the profile of distribution of their values into the specimen. They were performed using hardness tester Buehler Micromet II in Vickers scale on polished surface of laser tracks' cross sections' axes, perpendicularly to treated surface. Arrangement of measurements depended on observed remelted depth. First measuring point is $30 \mu \mathrm{m}$ from the surface. Research was carried out with nominal load $F=0,05 \mathrm{kgf}$ (approximately $0,49 \mathrm{~N}$ ).

\section{Results and discussion}

\subsection{OM Microstructure and geometrical parameters}

In Figures 2, 3, 4 structure of laser borided layer is shown respectively with variable $P$, $v_{l}$ and $d_{l}$. Structures were observed with optical microscope.
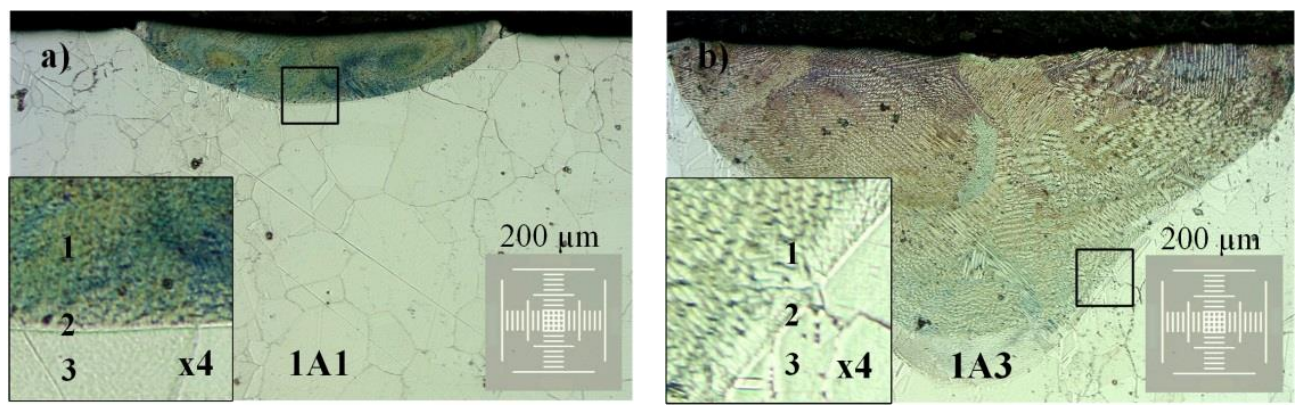

Fig. 2. OM structure of laser-borided Nimonic 80A-alloy at different laser beam power of:

a) $1,04 \mathrm{~kW}$, b) $2,08 \mathrm{~kW} .1$ - re-melted zone, 2 - heat-affected zone, 3 - substrate. 
Within laser tracks borided layers without visible discontinuations and failures were obtained. Borided layer (1) is noticeably different than the substrate (2). Heat affected zone is visible in specimens with high zoom as the thin line just under borided zone. In some Figures (for example 2 a) or 3 c) traces corresponding to movement of fluid (melted material) which occur during laser treatment can be observed. This movement is the effect of very high temperature gradient in location of absorption of radiation energy and it is called convection current. As the result of convection and gravity very quick mixing of fluid occurs.
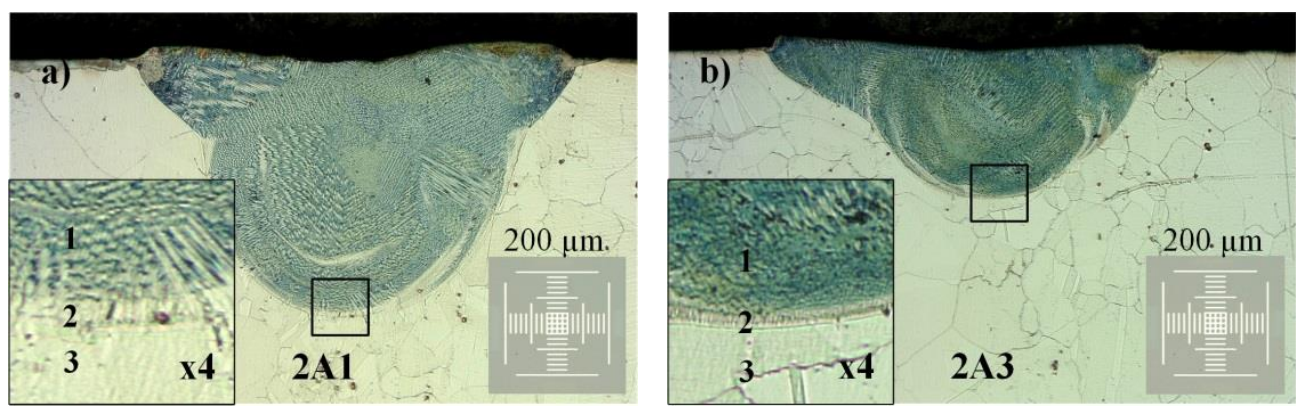

Fig. 3. OM structure of laser-borided Nimonic $80 \mathrm{~A}$-alloy at different laser scanning velocity of: a) $1,28 \mathrm{~m} / \mathrm{min}$, b) $3,84 \mathrm{~m} / \mathrm{min}$. 1 - re-melted zone, 2 - heat-affected zone, 3 - substrate.

Low melting temperature of Nimonic $80 \mathrm{~A}$ alloy $\left(1320-1365^{\circ} \mathrm{C}\right)$ and high power density of focused beam provided precise mixing of boron paste with the substrate in whole remelted cross section. Laser treatment led to very intense fragmentation of microstructure and forming groups of oriented dendrites. Borided layers are free of cracks. In cross section of $3 \mathrm{~A} 1$ specimen pores of large surfaces were observed (black spots in Figure 4 a).
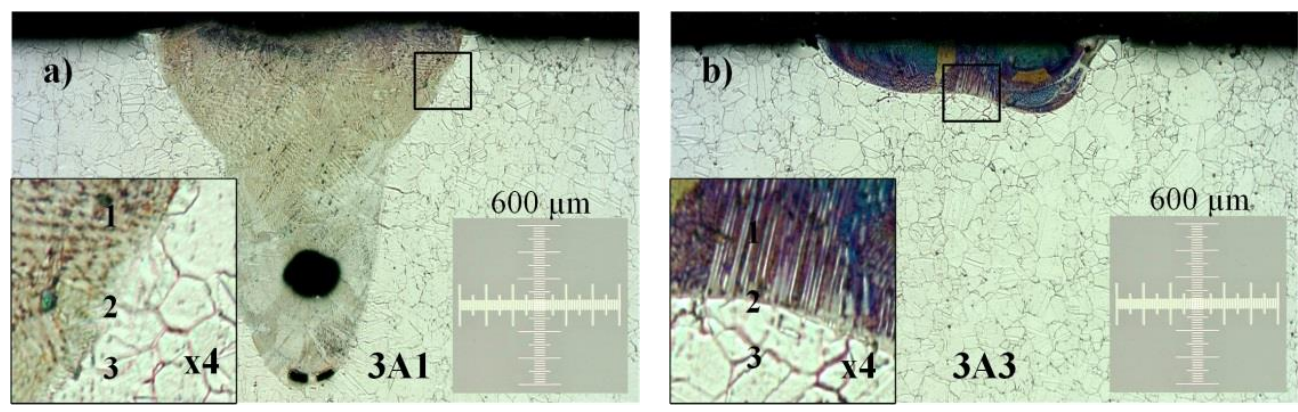

Fig. 4. OM structure of laser-borided Nimonic 80A-alloy at different laser beam diameter of: a) 1,0 mm, b) 2,0 mm. 1 - re-melted zone, 2 - heat-affected zone, 3 - substrate.

\subsection{SEM microstructure and EDS microanalysis}

Detailed analysis of borided layer was carried out using SE pictures (Figure 5). Areas near surface of borided layer (Fig. $5 \mathrm{~b}$ ) and $5 \mathrm{c}$ ) have similar, very fragmented structure. Two types of borides are visible: light-grey prevailing phase and dark-grey dendritic phase. Deeper into borided layer (Fig. $5 \mathrm{~d}$ ) structure is lesser fragmented and dendrites are larger.

Basing on EDS analysis it was found that lighter phase contains more nickel and titanium (point 3 in Fig. 6) than darker phase (point 1 in Fig. 6). Nickel borides $\left(\mathrm{Ni}_{3} \mathrm{~B}\right.$ and $\mathrm{Ni}_{2} \mathrm{~B}$ ) are dominant in this phase. More chromium occurs in in darker phase than in lighter one. Additionally, darker dendritic phase contains more boron and probably chromium borides $\left(\mathrm{CrB}\right.$ or $\left.\mathrm{Cr}_{2} \mathrm{~B}\right)$. 
b)

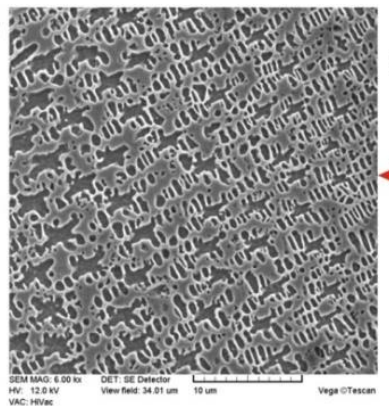

c)

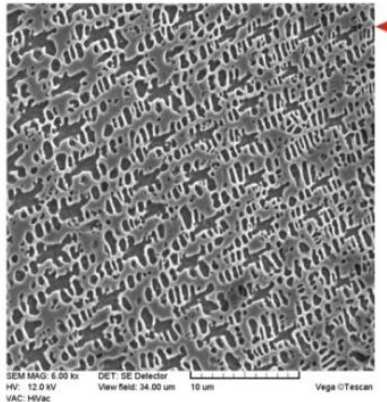

a)

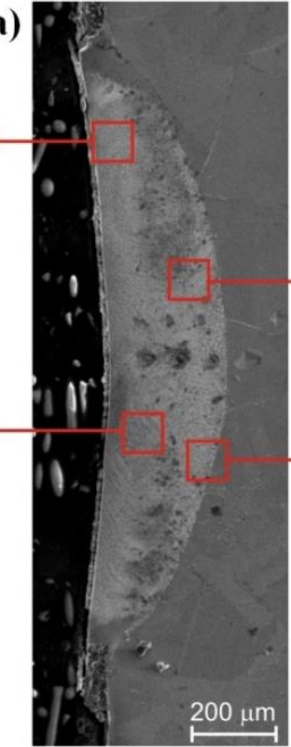

d)

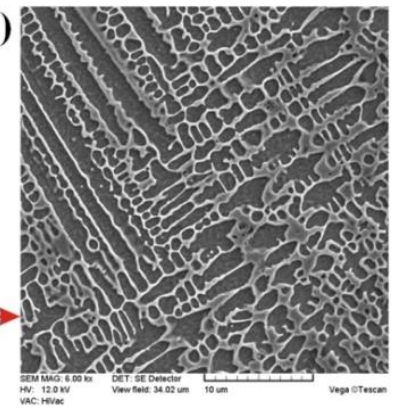

e)

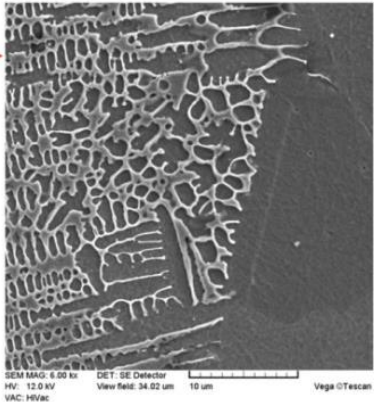

Fig. 5. SE images of laser-borided layer formed on Nimonic 80A-alloy (attempt 1A1).

Content of borides is low due to small thickness of boron layer before the treatment. Remelted and raw structures intermingle (Fig. 5 e). Linear X-ray microanalysis confirmed that with increasing nickel content, chromium content decreases in whole cross section of borided layer.

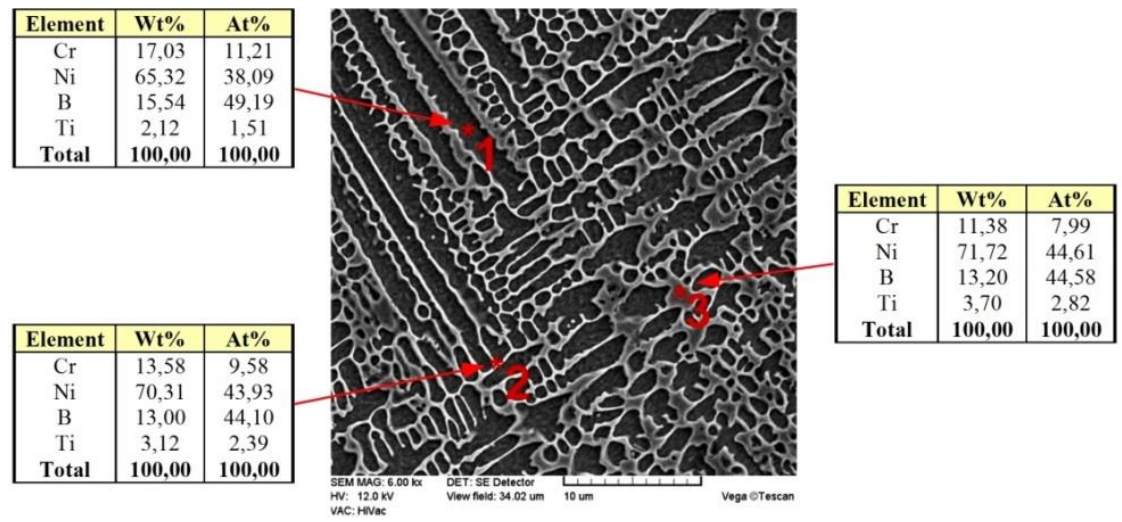

Fig. 6. The results of EDS analysis for different phases visible in SE images.

\subsection{Geometrical parameters}

Value of applied laser beam power $P$ (Fig. 2) strongly affects the size of re-melted zone. Doubling laser beam power (to $2,08 \mathrm{~kW}$ ) led to increase width of laser track from 0,69 to $1,21 \mathrm{~mm}$. Depth increased about five times (from 0,11 for $P=1,04 \mathrm{~kW}$ to $0,57 \mathrm{~mm}$ for $P=$ $2,08 \mathrm{~kW}$ ). Laser beam scanning velocity $v_{l}$ (Fig. 3) has lower influence on size of borided zone. Threefold increase of $v_{l}$ results in insignificant change of laser track width from 0,84 $\mathrm{mm}$ for $v_{l}=1,28 \mathrm{~m} / \mathrm{min}$ to $0,74 \mathrm{~mm}$. Depth decreased respectively from $0,4 \mathrm{~mm}$ to 0,23 
$\mathrm{mm}$. In case of various laser beam diameter $d_{l}$ (Fig. 4) measured on treated surface, its decrease causes an increase of re-melted zone's depth. It is especially seen during change of this value from $d_{l}=1,5 \mathrm{~mm}$ to $d_{l}=1 \mathrm{~mm}$. It caused an increase of depth from $0,29 \mathrm{~mm}$ to $1,36 \mathrm{~mm}$ respectively. The phenomenon of increasing width both in case of increasing and decreasing $d_{l}$ is particularly interesting. If $d_{l}=1 \mathrm{~mm}$ cross section of laser track has a shape of letter $T$ and dimensions of width and depth significantly vary from projected values. It is possible to sublimate the substrate by very high power density in large depth, generate vapours limiting the impact of laser beam and melting the surface with higher width. In summary, laser beam power increase lead to growth of re-melted zone and an increase of laser beam power density results in decrease of dimensions.

\subsection{Microhardness profile}

Microhardness measurements taken in cross sections of specimens in areas free of modifications due to laser treatment allowed to determine an average value of the substrate $-80 \mathrm{~A}$ - which is equal to $326 \mathrm{HV} 0,05$. Value of microhardness in area laser treated with insufficient boron content in relation to re-melted zone size is lower than microhardness of the substrate. In case of this material creation of fine-grained structure leads to decrease of microhardness. Figure 7 present microhardness profiles for performed tests in which first of them (a) concerns an examination of influence of laser beam power values. Average values $549 \mathrm{HV}, 420 \mathrm{HV}$ and $304 \mathrm{HV}$ were obtained in order of respectively the treatment with increasing laser beam power. Treatment with low laser beam power allowed to obtained high hardness in whole depth due to low re-melted volume and increased percentage boron content. Near the bottom of re-melted zone hardness additionally increases. Change in laser beam scanning velocity (b) does not affect obtained results significantly. For the lower laser beam scanning velocity an average value equal to $432 \mathrm{HV}$ was obtained, for medium 490 $\mathrm{HV}$ and for the highest $-551 \mathrm{HV}$. In chapter about geometrical features it was spotted that for laser beam diameter $d_{l}=1 \mathrm{~mm}$ very large cross section of laser track was obtained. Due to low percentage boron content in this re-melted zone and structure fragmentation average microhardness of $233 \mathrm{HV}$ was measured (c). Obtained distribution is not linear, increase in hardness occurs in depth of $0,6 \mathrm{~mm}$. In case of laser beam diameter $d_{l}=2 \mathrm{~mm}$ average microhardness equal to $525 \mathrm{HV}$ was obtained with very high value of $660 \mathrm{HV}$ near the surface. The most desirable microhardness profile, taking into consideration values of each measurements and their distribution in laser track's cross section was obtained after the treatment with parameters 2A2, 2A3 and 3A3 (according to Table 2).
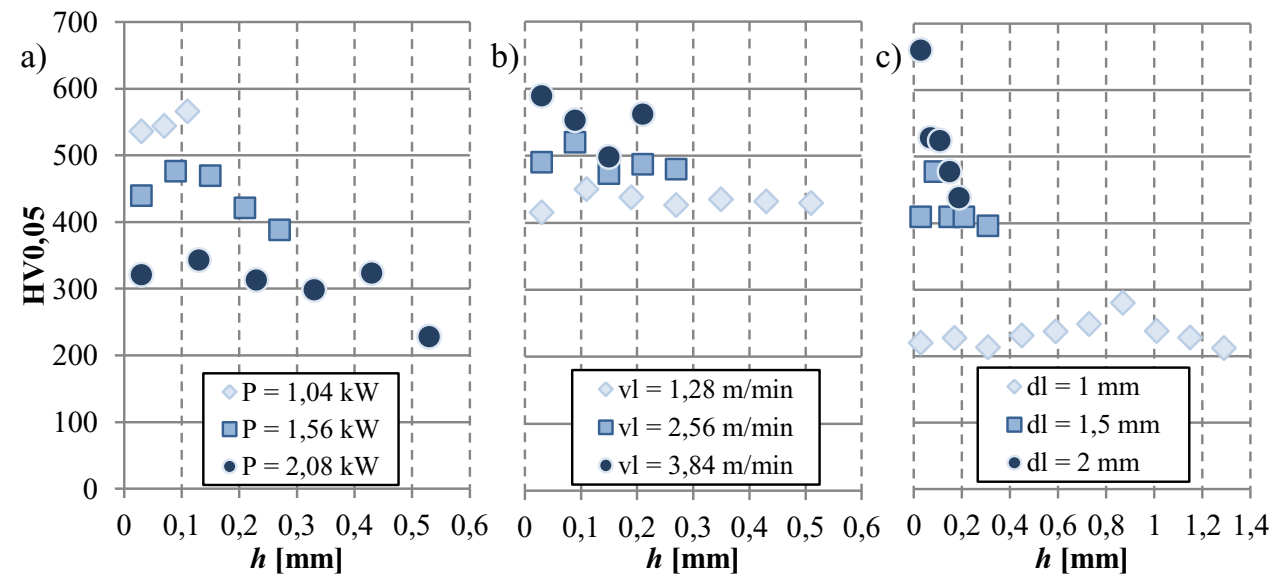

Fig. 7. The microhardness profiles of laser-borided layers formed on Nimonic80A-alloy. 


\section{Summary and conclusions}

Laser treatment with $\mathrm{CO}_{2}$ laser modified the structure of Nimonic $80 \mathrm{~A}$ in which generally two different areas can be distinguished: borided and untreated, without distinctly visible heat affected zone. EDS analysis confirmed presence of two phases in which nickel and chromium - two main components of Nimonic 80A alloy, are dominant respectively. With increasing nickel content, chromium content decreases. In phases containing more chromium, boron content is also higher which proves higher affinity of boron for chromium. If there is no boron or if its content is low microhardness decreases under microhardness of untreated Nimonic 80A. Results of this research serve as an indicator of laser boriding process flow and the influence of parameters on its effects. Industrial application requires optimization of parameters and layer thickness of paste with boron in order to obtain higher hardness, suitable thickness and surface quality. Used thickness of 30 $\mu \mathrm{m}$ is too low which allows to develop research using various layer thicknesses. An influence of laser treatment parameters on geometrical cross section of re-melted zone is significant. To reduce differences in structure hardness and obtain effect similar to boriding, it is necessary to apply equal dilution ratio. This means that in case of deeper remelting thicker layer of boron paste should be applied. This paper allows to predict thicknesses of layers before the treatment.

\section{References}

1. R. R. Adharapurapu, D. Kumar, J. Zhu, T. M. Pollock, Corros. Sci. 53, 388 (2011)

2. S. Hayashi, C. Matsukawa, H. Yakuwa, T. Kishikawa, Corros. Rev. 36, 75 (2018)

3. S. Chollet, L. Pichon, J. Cormier, J.B. Dubois, Surf. Coat. Technol. 235, 318 (2013)

4. P. K. Aw, A. W. Batchelor, N. L. Loh, Surf. Coat. Technol. 89, 70 (1997)

5. C. Leroy, T. Czerwiec, C. Gabet, T. Belmonte, Surf. Coat. Technol. 142, 241 (2001)

6. D. Przestacki, T. Chwalczuk, S. Wojciechowski, Int. J. Adv. Manuf. Technol. 91, 3887 (2017)

7. S. Wojciechowski, D. Przestacki, T. Chwalczuk, MATEC Web of Conferences, 136, 01006 (2017)

8. D. Przestacki, T. Chwalczuk, MATEC Web of Conferences, 136, 02006 (2017)

9. M. Kawalec, D. Przestacki, K. Bartkowiak, M.Jankowiak, 27 th ICALEO 2008, Congress Proceedings, 895 (2008)

10. D. Przestacki, M. Jankowiak, Procedia CIRP, 14, 229 (2014)

11. M. Kulka, N. Makuch, M. Popławski, Surf. Coat. Technol. 244, 78 (2014)

12. D. Przestacki, R. Majchrowski., L. Marciniak-Podsadna, Appl. Surf. Sci. 388, 420 (2016)

13. A. Bartkowska, A. Pertek, M. Poplawski, D. Bartkowski, D. Przestacki, A. Miklaszewski, Opt. Las. Technol. 72, 116 (2015)

14. M. Kulka, D. Mikolajczak, N. Makuch, P. Dziarski, Surf. Coat. Tech. 291, 292 (2016)

15. N. Makuch, M. Kulka, P. Dziarski, D. Przestacki, Opt. Las. Eng. 57, 64 (2014)

16. R. Filip, J. Sieniawski, E. Pleszakov, Surf. Eng. 22, 53 (2006)

17. M. Kulka, P. Dziarski, N. Makuch, A. Piasecki, App. Surf. Sci 284, 757 (2013)

18. N. Makuch, A. Piasecki, P. Dziarski, M. Kulka, Opt. Las. Technol. 75, 229 (2015) 